Published in final edited form as:

Cancer Causes Control. 2015 October ; 26(10): 1467-1476. doi:10.1007/s10552-015-0645-x.

\title{
Television Watching and Colorectal Cancer Survival in Men
}

Yin Cao, MPH, ScD ${ }^{1}$, Jeffrey A. Meyerhardt, MD, MPH ${ }^{2}$, Andrew T. Chan, MD, MPH $^{3,4}$, Kana Wu, MD, PhD ${ }^{1}$, Charles S. Fuchs, MD, MPH ${ }^{2,3}$, and Edward L. Giovannucci, MD, ScD $1,3,5$

${ }^{1}$ Department of Nutrition, Harvard T. H. Chan School of Public Health, Boston, MA

${ }^{2}$ Department of Medical Oncology, Dana-Farber Cancer Institute and Harvard Medical School, Boston, MA

${ }^{3}$ Channing Division of Network Medicine, Brigham and Women's Hospital and Harvard Medical School, Boston, MA

${ }^{4}$ Division of Gastroenterology, Massachusetts General Hospital, Boston, MA

${ }^{5}$ Department of Epidemiology, Harvard T. H. Chan School of Public Health, Boston, MA

\section{Abstract}

Purpose-To assess the association between pre- and postdiagnostic time spent sitting watching TV as well as other sedentary behaviors (other sitting at home and at work/driving) and mortality from colorectal cancer or other causes, and overall mortality.

Methods-We followed stage I-III colorectal cancer patients from the Health Professionals Follow-up Study (1986-2010). Cox models were used to calculate hazard ratios (HRs) and 95\% confidence intervals (CIs).

Results-926 and 714 patients were included in the analysis of pre- and postdiagnostic TV watching respectively, and 471 and 325 died during follow-up. Prolonged prediagnostic TV viewing was associated with increased risk of colorectal cancer-specific mortality independent of leisure-time physical activity. The HRs (95\% CIs) for 0-6, 7-13,14-20 and $\geq 21 \mathrm{~h} /$ wk were 1.00 (referent), 0.84 (0.56-1.25), $1.15(0.75-1.78), 2.13(1.31-3.45)\left(\mathrm{P}_{\text {trend }}=0.01\right)$. The association was observed primarily among overweight and obese individuals. Prediagnostic TV watching was also associated with overall mortality within 5 years of diagnosis, largely due to the association with colorectal cancer mortality. Other prediagnostic sitting at home or at work/driving was not associated with mortality. Postdiagnostic TV viewing was associated with non-significant increased risk of colorectal cancer-specific mortality (HR for $221 \mathrm{vs} 0-6 \mathrm{~h} / \mathrm{wk}=1.45$; $95 \% \mathrm{CI}$ 0.73-2.87) adjusting for TV viewing before diagnosis.

Conclusion-Prolonged prediagnostic TV watching is associated with higher colorectal cancerspecific mortality independent of leisure-time physical activity among colorectal cancer patients.

Corresponding Author: Yin Cao, Department of Nutrition, Harvard T. H. Chan School of Public Health, 665 Huntington Avenue, Boston, MA 02115, United States; yic576@mail.harvard.edu; Telephone: +1-617-4153586.

Authors' Potential Conflicts of Interest: None.

Previous Presentation: The manuscript was presented in part as a poster in the Thirteenth Annual AACR International Conference on Frontiers in Cancer Prevention Research, New Orleans, 2014. 


\section{Keywords}

sedentary behavior; television watching; colorectal cancer; survival

\section{INTRODUCTION}

Sedentary behaviors, characterized by an energy expenditure $₫ .5$ METs (metabolic equivalent of task) while in a sitting or reclining posture, are increasingly prevalent in modern society (1). These include sitting, lying down, reading, driving, watching television (TV), and other forms of screen-based entertainment. Although TV watching itself does not represent the entire spectrum of sedentary behaviors, it is the most widespread leisure-time sedentary behavior of adults in the U.S. and other western countries (2-4) and is effective in ranking individuals by sedentary lifestyle $(5,6)$. Indeed, epidemiologic studies have linked time spent watching TV with cardio-metabolic biomarkers $(5,7,8)$ and increased risk of obesity, diabetes (9-12), cardiovascular disease $(13,14)$, and all-cause mortality $(3,14)$, independent of physical activity levels. Stronger associations with TV viewing time than with occupational sitting time were also observed $(10,15)$. A higher likelihood of having eating patterns linked to commercial advertisement and food cues appearing on TV may partially explain the additional deleterious effect of prolonged TV viewing (10).

The role of sedentary behaviors in colorectal carcinogenesis is of particular interest as obesity and diabetes are established risk factors for colorectal cancer (16-20). Although data suggest modest positive associations of sitting time with risk of incident colorectal cancer (21-23), studies among colorectal cancer survivors are limited. Campbell et al reported that $\checkmark 6 \mathrm{~h} / \mathrm{d}$ of total leisure-time sitting (including sitting driving or sitting in a car/bus/train; sitting watching TV; and sitting at home reading) compared with $<3 \mathrm{~h} / \mathrm{d}$ was associated with colorectal-specific mortality (pre- and postdiagnosis hazard ratio [HR] and 95\% CI: 1.33 (0.96-1.84) and $1.62(1.07-2.44)$ ) and higher all-cause mortality (pre- and postdiagnosis HR and 95\% CI: $1.36(1.10-1.68)$ and $1.27(0.99-1.64))(24)$. Recently, Arem et al (25) examined TV watching explicitly, and found that TV watching before diagnosis was associated with all-cause mortality (HR for $\geq 5 \mathrm{vs} 0-2 \mathrm{~h} / \mathrm{d}=1.22$; 95\% CI 1.06-1.41) but a non-significant increased risk of colorectal cancer mortality (HR=1.18; 95\% CI, 0.82-1.68); whereas postdiagnosis TV watching was associated with non-significantly increased risk of all-cause mortality ( $\mathrm{HR}=1.25 ; 95 \% \mathrm{CI} 0.93-1.67)$ and colorectal cancer mortality $(\mathrm{HR}=1.45$; 95\% CI 0.85-2.47).

In this study, we assessed the association between time spent sitting while watching TV and colorectal cancer-specific and overall mortality among individuals diagnosed with nonmetastatic enrolled in the Health Professionals Follow-up Study (HPFS), 1986-2010. We also assessed the influence of other sitting at home and at work/driving. 


\section{METHODS}

\section{Study population}

The HPFS is a cohort study of 51,529 US male health professionals aged 40-75 years at enrollment in 1986. Participants have been mailed questionnaires every 2 years since baseline to collect data on demographics, lifestyle factors, medical history, and disease outcomes, and every 4 years to report update in dietary intake. The overall follow-up rate was greater than $94 \%$ and ascertainment of deaths was more than $98 \%$ complete(26).

\section{Ascertainment of colorectal cancer diagnosis}

On each biennial follow-up questionnaire, participants were asked whether they had a diagnosis of colorectal cancer during the prior 2 years. When a participant (or the next of kin for decedents) reported colorectal cancer, we sought permission to obtain medical records and pathology reports. Study physicians, blinded to exposure data, reviewed all medical records related to colorectal cancer and recorded the disease stage, histologic findings, and tumor location. For nonresponders, we searched the National Death Index to discover deaths and to ascertain any diagnosis of colorectal cancer that contributed to death or was a secondary diagnosis.

In total, 1222 men were diagnosed as having colorectal cancer in the HPFS between January 1986 and January 2010; we excluded 191 men with metastatic colorectal cancer at the time of diagnosis. Of 1031 remaining men, 926 reported prediagnostic TV viewing time and 720 reported average hours of sitting watching TV between 6 months and 3 years after diagnosis. To minimize bias by occult recurrences or other undiagnosed major illnesses, we excluded 6 men who died within 6 months of their postdiagnosis TV watching assessment. A total of 714 men were eligible for the analysis of postdiagnostic TV viewing.

\section{Assessment of TV watching and other sedentary behaviors}

Starting from 1988, participants reported their average weekly time spent sitting watching TV (including videotapes) biennially. The 1988 questionnaire included 6 response categories (ranging from $0-1$ to $\geq 40 \mathrm{~h} / \mathrm{wk}$ ). Beginning in 1990, biennial questionnaires included 13 response categories (ranging from 0 to $\geq 40 \mathrm{~h} / \mathrm{wk}$ ) for time spent sitting watching TV as well as sitting at work, driving, and other sitting at home (including reading, eating, or at desk) respectively using the same response categories as TV watching. Similar assessment of sedentary behaviors was used in the Nurses' Health Study and was found to be associated with increased risk of obesity and diabetes (10). We also reported previously that in a sample of participants the average number of hours of TV watching reported in 1994 was significantly positively associated with low density lipoprotein cholesterol and significantly inversely associated with HDL cholesterol and apolipoprotein A1(5).

To capture long-term sitting behavior, we calculated cumulative average hours of sitting (TV watching, at work/driving, and other sitting at home) up to the time of diagnosis in the analyses of prediagnostic sedentary behavior. The median time from baseline to diagnosis was 11 years. As a sensitivity analysis, the response from the immediate prior survey was used (median, 12 months before diagnosis). For postdiagnosis analyses, the first assessment 
collected at least 6 months after diagnosis (median, 17 months after diagnosis) was used to avoid assessment during the period of active treatment but within the period of highest likelihood of recurrences.

\section{Assessment of physical activity and other covariates}

Every 2 years, participants were asked to report the average amount of time they spent per week on each of the following activities: walking, jogging, running, bicycling, calisthenics or use of a rowing machine, lap swimming, squash or racquetball, and tennis, as well as usual walking pace. From this information, weekly energy expenditure in metabolic equivalent hours (MET-hrs) was calculated (27). Information of body mass index (BMI), smoking, regular aspirin use, alcohol, folate, calcium, red meat intake, and energy intake was also obtained from the biennial questionnaire and considered in multivariable analyses as potential confounders.

\section{Measurement of mortality}

Men were followed up until death or December 31, 2011, whichever came first. Ascertainment of deaths included reporting by the family or by postal authorities. In addition, the names of consistent nonresponders were searched in the National Death Index (28). The cause of death was assigned by study physicians blinded to exposure data. In the case of men who died of colorectal cancer not previously reported, we obtained medical records of the colorectal cancer diagnosis after receiving permission from the next of kin. More than $98 \%$ of deaths in the HPFS have been identified using these methods (28).

\section{Statistical analysis}

In the main analysis, death from colorectal cancer was the primary end point, and deaths from other causes were censored. In secondary analyses, death from causes other than colorectal cancer and deaths from any cause were the end points. We estimated the Spearman correlation coefficients between pre- and postdiagnostic TV watching, and between TV watching and BMI and physical activity. Due to limited number of colorectal cancer-specific deaths among patients who had a postdiagnosis TV measurement, the primary exposure of interest was sedentary behavior before the diagnosis of colorectal cancer. Participants were followed up from diagnosis in prediagnostic analysis or beginning 6 months from the date of the first postdiagnostic TV watching assessment for postdiagnostic analysis, to death or December 31, 2011, whichever came first. Four categories of sitting time were coded consistently across all questionnaires $(0-6,7-13,14-$ $20, \geq 21 \mathrm{~h} / \mathrm{wk})$. Test for trend was conducted using continuous hours of sitting time. Departures from the proportional hazards assumption were tested by likelihood ratio tests comparing models with and without the interaction terms of survival time by categories of sitting behavior. No significant violation was detected.

Kaplan Meier curves were plotted and log-rank tests were performed. Cox proportional hazards models were used to calculate hazard ratios (HRs), adjusting for other risk factors for cancer survival, including age at diagnosis (year), years of diagnosis (prior to 1990, 1990-1999, 2000+), stage (I, II, III, missing and not metastatic), grade (well, moderate, poor/undifferentiated, unknown), tumor location (rectal, colon) and smoking status (never, 
past, current). We also examined whether established or probable risk factors for colorectal cancer, including regular aspirin use (yes/no), alcohol ( $<5,5-<30,330 \mathrm{~g} / \mathrm{d}$ ), folate (in tertiles), calcium (in tertiles), red meat intake (in tertiles), and energy intake (in tertiles), affect the associations of interest. We adjusted for leisure-time physical activity $(<9,9-<18$, 18-<27, 27 MET-hrs/wk) to assess whether the influence of sedentary behaviors were distinct from physical activity, which was inversely associated with colorectal-cancer specific and overall mortality (29).

We adjusted for BMI $\left(\mathrm{kg} / \mathrm{m}^{2}\right.$ in quintiles $)$ to explore whether it mediates the association of interest. To fully assess whether observed associations may be explained by unhealthy diet, we adjusted for Alternate Health Eating Index(AHEI)-2010, an updated composite score from the original AHEI (30), which features higher consumption of vegetables (excluding potatoes), whole fruit, whole grains, nuts and legumes, long chain omega-3 fatty acids, polyunsaturated fat; and a lower consumption of sugar-sweetened beverages, red/processed meat, sodium, trans fat, and moderate alcohol consumption. Adherence to the AHEI-2010 was associated with reduced risk of major chronic diseases (31). For prediagnostic analysis, cumulative average (when applicable) of the potential confounders up to the time of diagnosis was used, and first assessment after diagnosis was used for postdiagnostic analysis.

We examined if the association between TV watching and colorectal-cancer specific mortality differed by age at diagnosis ( $<70 \mathrm{y}$ vs $\geq 70 \mathrm{y}$ ), stage (I/II vs III vs missing, not known to be metastatic), tumor location (colon vs rectum), year of diagnosis (before $2000 \mathrm{vs}$ after 2000), physical activity ( $<18$ vs $\geq 18$ MET-hrs/wk), and BMI ( $<25 \mathrm{vs} \geq 25 \mathrm{~kg} / \mathrm{m}^{2}$ ). We evaluated interaction by entering a product term of continuous TV watching and the above variables. $\mathrm{P}$ value for interaction was determined by a log likelihood ratio test comparing the models with and without the interaction terms.

Since most of deaths due to colorectal cancer occur within 5 years after diagnosis, we conducted sensitivity analysis to evaluate whether prolonged prediagnostic TV watching was associated with higher mortality within 5 years of diagnosis. All the analyses were performed using SAS v 9.3 (SAS Institute, Cary, NC), and the statistical tests were twosided.

\section{RESULTS}

A total of 926 and 714 eligible colorectal cancer patients were included in the analysis of prediagnostic and postdiagnostic TV watching, respectively. Patients who watched TV for longer time before diagnosis spent more time in other sedentary behaviors at home, engaged in fewer physical activities, and lower dietary scores (Table 1). Patterns of these factors were less obvious across TV watching after diagnosis. Using continuous variables, prediagnostic TV watching was modestly correlated with $\mathrm{BMI}(\mathrm{r}=0.12, \mathrm{P}<0.001)$ and physical activity $(\mathrm{r}=-0.08, \mathrm{P}=0.01)$, whereas postdiagnostic $\mathrm{TV}$ viewing time was not correlated with $\mathrm{BMI}(\mathrm{r}=0.07, \mathrm{P}=0.07)$ and physical activity $(\mathrm{r}=-0.005, \mathrm{P}=0.88)$. No appreciable differences of tumor characteristics were observed for either pre- or postdiagnostic TV viewing. 


\section{Prediagnostic TV watching, other sedentary behaviors and mortality}

More time spent sitting watching TV before diagnosis was significantly associated with increased risk of colorectal cancer-specific mortality and non-significantly elevated overall mortality after adjusting for age and year of diagnosis, stage, grade and location of the tumor, and smoking status (Table 2). Further adjusting for leisure-time physical activity or other known or suspected risk factors for colorectal cancer, including regular use of aspirin, alcohol, folate, calcium, red meat and energy intake did not appreciably change the estimates. BMI and dietary score minimally mediated the observed association. The HRs (95\% CIs) of colorectal cancer-specific mortality across categories of prediagnostic TV watching $(0-6,7-13,14-20, \geq 21 \mathrm{~h} / \mathrm{wk})$ were 1.00 (referent), 0.84 (0.56-1.25), 1.15 (0.751.78), 2.13 (1.31-3.45) ( $\mathrm{P}$ for trend=0.01) (Table 2 and Figure 1). When the response from the immediate survey prior to diagnosis was used instead of cumulative average TV watching time, the effect estimates were similar (Supplemental Table 1).

To examine whether the association with colorectal cancer-specific mortality differed according to tumor or patient characteristics, we combined the first three categories of TV watching (HR for $\geq 21 \mathrm{vs}<21 \mathrm{~h} / \mathrm{wk}=2.20$; 95\% CI 1.43-3.38) based on the observed dose response relationship. The association was primarily observed among overweight and obese men (BMI $\geq 25 \mathrm{~kg} / \mathrm{m}^{2}$ ) but not among patients with BMI $<25 \mathrm{~kg} / \mathrm{m}^{2}\left(\mathrm{P}_{\text {interaction }}=0.05\right)$. The hazard ratio estimates were similar for cases diagnosed before and after age 70, stage I\&II and stage III cancer, colon and rectal cancer, cancer diagnosed before and after 2000, and those engaged in $<18$ and $\geq 18$ MET-hrs per week of physical activity (Figure 2).

When restricted to mortality within 5-year after diagnosis, prolonged TV watching before diagnosis was also associated with higher overall mortality (HR for $\geq 21 \mathrm{vs}<21 \mathrm{~h} / \mathrm{wk}=1.56$; 95\% CI 1.04-2.33) (Supplemental Table 2).

Neither sitting at home nor sitting at work/driving was associated with colorectal cancerspecific or overall mortality (Supplemental Table 3).

\section{Postdiagnostic TV watching and mortality}

Time spent sitting watching TV after diagnosis was correlated with prediagnostic TV viewing time $(r=0.54, \mathrm{p}<0.001)$. Although power was limited, postdiagnostic time spent sitting watching TV was associated with non-significant increased risk of colorectal cancerspecific mortality even after adjusting for prediagnostic TV watching (HR for $21 \mathrm{vs} 0-6 \mathrm{~h} /$ $w \mathrm{k}=1.45 ; 95 \%$ CI 0.73-2.87) (Table 3).

\section{DISCUSSION}

In this cohort of male colorectal cancer patients, excessive sitting watching TV before diagnosis was significantly associated with an increased risk for colorectal-cancer specific mortality, independent of levels of leisure-time physical activity. Postdiagnostic time spent sitting watching TV was associated with nonsignificant increased risk of colorectal cancerspecific mortality. 
Emerging evidence suggests that, distinct from physical activity, excessive TV viewing time have adverse health consequences among colorectal cancer survivors $(7,25)$. However, comparison across these studies is challenging owing to heterogeneities in the referent group selected, range of sedentary time, timing of assessment, and length of follow up. Arem et al (25) found that baseline TV watching (median, 5 years) before diagnosis was associated with all-cause mortality but non-significant increased risk of colorectal cancer mortality. In comparison, we utilized repeated measurement of TV watching and other covariates before diagnosis to reflect long-term behavior, and found that prolonged TV watching was associated with colorectal mortality but not all-cause mortality. More research is needed.

In our analysis, a significant association between TV watching but not sitting at work and colorectal cancer survival was observed. Similar stronger associations with TV viewing time were also suggested for obesity and diabetes (10). Leisure-time sitting or sitting at work may have distinct roles in disease etiology. It is also possible that sitting watching TV or at work is associated differentially with other disease-related correlates (8). One hypothesis is that prolonged TV watching was associated with increased consumption of unhealthful food ( 9 , 10,32 ); however, in our study, the positive significant association persisted after adjusting for dietary factors. Additional reasons underlying these observations merit further exploration.

Similar to Arem et al, we reported that prolonged sitting TV viewing time after colorectal cancer diagnosis was associated with a non-significant increased risk of colorectal cancer mortality, and the association was attenuated after adjusting for prediagnostic TV watching. In addition, we also observed a stronger association between prediagnostic TV watching, either cumulative average exposure up to diagnosis or a single most recent measurement before diagnosis, and colorectal cancer-specific mortality, when compared to the first assessment after diagnosis, suggesting that TV watching may have long-term effects on colorectal cancer progression (i.e. enhances the likelihood that metastatic cells may have seeded before the diagnosis and removal of colorectum). Limited power may also partially explain the non-significant increased risk for postdiagnostic TV watching. Whether reducing TV viewing time after diagnosis would be beneficial for colorectal cancer prognosis requires additional research.

Pathways through which sedentary behaviors affect risk and progression of colorectal cancer are yet to be investigated. Obesity may represent an intermediate step (33). A study among Australian colorectal cancer survivors suggests that watching $\geq 5 \mathrm{~h}$ vs $2 \mathrm{~h}$ of TV per day was associated with a mean increase in BMI $0.71 \mathrm{~kg} / \mathrm{m}^{2}$ over approximately 18 months (34). In our analysis, adjusting for BMI did not materially alter the association observed, but the association between prediagnostic TV watching and increased colorectal cancer mortality was observed primarily among overweight and obese patients. Because BMI is not an optimal indicator of overweight and obesity in the elderly (35), the possibility that sedentary behaviors correlates more with visceral adiposity could not be ruled out. In fact, prospective studies in both the US and Australia have found associations between TV viewing and increased waist circumference $(36,37)$, which reflects both subcutaneous and visceral adipose. Inflammation may also involve in the link between sedentary behaviors and colorectal cancer progression. C-reactive protein, a general marker of inflammation was 
recently observed to be positively associated with sedentary time $(15,38)$ and colorectal cancer-specific mortality (39).

Strengths of our study include the ability to capture long-term prediagnostic sedentary behavior, minimizing measurement errors through detailed assessments of time spent "sitting" watching TV while excluding TV viewing coupled with other non-sedentary activities (e.g. cooking, on treadmills). We were also able to differentiate domains in which sedentary behavior occurs and control for a variety of potential confounders and mediators. Advantages also included prospective collection of exposure and covariate data and the comprehensive medical record review of self-reported colorectal cancer and of deaths.

Our study had several limitations. First, sedentary behaviors were self-reported. However, objective measurements (i.e. accelerometer) alone are unable to identify the domains in which behavior occurs. Future research may benefit from combining self-reports and objective measures. Secondly, although the average hours of sitting watching TV (11 h/wk) was lower than the national estimates ( $34 \mathrm{~h} / \mathrm{wk}$ in adults aged 50-64) (4) and we had limited number of patients with high levels of TV watching, a widespread distribution of TV viewing time in our study (an average of $4 \mathrm{~h} / \mathrm{wk}$ among the least and $27 \mathrm{~h} / \mathrm{wk}$ in the most sedentary men) allowed us to assess the potential health benefit of a less sedentary lifestyle. Assessment of time spent sitting at computer and/or other screens (e.g. tablets, smart phones), the increasingly prevalent sedentary behaviors may also be informative. Thirdly, treatment data were not collected. However, fairly homogenous nature of this cohort (male health professionals) would likely increase the probability of at least standard therapy which would be expected to be closely correlated with stage at diagnosis (40). Additionally, possibility of residual confounding, especially from physical activity, could not be ruled out even though our leisure-time physical activity questions have been previously validated and occupational physical activities engaged by these health professionals were limited. Finally, our data are limited in power to assess the influence of post-diagnosis TV watching.

In conclusion, independent of leisure-time physical activity, prolonged TV watching before diagnosis was associated with poorer colorectal cancer survival and postdiagnostic TV viewing was associated with a non-significant increased risk of colorectal cancer-specific mortality. As intention to make positive lifestyle adjustments by engaging more physical activity have been noted among cancer survivors $(41,42)$, reducing sedentary time, in particular TV viewing time, may confer benefits to patients with colorectal cancer.

\section{Supplementary Material}

Refer to Web version on PubMed Central for supplementary material.

\section{ACKNOWLEDGEMENTS}

Funding: This work was supported by grants from the National Institute of Health (P01 CA87969; P01 CA55075; UM1 CA167552; R01 CA137178; K24 DK098311). Dr. Chan is a Damon Runyon Clinical Investigator. The study sponsors had no role in the design of the study; the collection, analysis, and interpretation of the data; the writing of the manuscript; and the decision to submit the manuscript for publication.

Additional Acknowledgements: We would like to thank the participants and staff of the Health Professionals Follow-Up Study for their valuable contributions as well as the following state cancer registries for their help: AL, 
AZ, AR, CA, CO, CT, DE, FL, GA, ID, IL, IN, IA, KY, LA, ME, MD, MA, MI, NE, NH, NJ, NY, NC, ND, OH, OK, OR, PA, RI, SC, TN, TX, VA, WA, WY. The authors assume full responsibility for analyses and interpretation of these data.

\section{REFERENCES}

1. Barnes J, Behrens TK, Benden ME, et al. Letter to the Editor: Standardized use of the terms "sedentary" and "sedentary behaviours". Appl Physiol Nutr Me. 2012; 37:540-542.

2. Grontved A, Hu FB. Television viewing and risk of type 2 diabetes, cardiovascular disease, and allcause mortality: a meta-analysis. JAMA : the journal of the American Medical Association. 2011; 305:2448-2455. [PubMed: 21673296]

3. Wijndaele $\mathrm{K}$, Brage $\mathrm{S}$, Besson $\mathrm{H}$, et al. Television viewing time independently predicts all-cause and cardiovascular mortality: the EPIC Norfolk study. International journal of epidemiology. 2011; 40:150-159. [PubMed: 20576628]

4. Nielsen. State of the Media: Trends in TV Viewing-2011 TV Upfronts. 2011

5. Fung TT, Hu FB, Yu J, et al. Leisure-time physical activity, television watching, and plasma biomarkers of obesity and cardiovascular disease risk. American journal of epidemiology. 2000; 152:1171-1178. [PubMed: 11130623]

6. Owen N, Healy GN, Matthews CE, Dunstan DW. Too much sitting: the population health science of sedentary behavior. Exercise and sport sciences reviews. 2010; 38:105-113. [PubMed: 20577058]

7. Lynch BM, Cerin E, Owen N, Hawkes AL, Aitken JF. Television viewing time of colorectal cancer survivors is associated prospectively with quality of life. Cancer Cause Control. 2011; 22:11111120.

8. Teychenne M, Ball K, Salmon J. Sedentary Behavior and Depression Among Adults: A Review. Int J Behav Med. 2011; 17:246-254. [PubMed: 20174982]

9. Hu FB, Leitzmann MF, Stampfer MJ, Colditz GA, Willett WC, Rimm EB. Physical activity and television watching in relation to risk for type 2 diabetes mellitus in men. Archives of internal medicine. 2001; 161:1542-1548. [PubMed: 11427103]

10. Hu FB, Li TY, Colditz GA, Willett WC, Manson JE. Television watching and other sedentary behaviors in relation to risk of obesity and type 2 diabetes mellitus in women. JAMA : the journal of the American Medical Association. 2003; 289:1785-1791. [PubMed: 12684356]

11. Krishnan S, Rosenberg L, Palmer JR. Physical activity and television watching in relation to risk of type 2 diabetes: the Black Women's Health Study. American journal of epidemiology. 2009; 169:428-434. [PubMed: 19056835]

12. Ford ES, Schulze MB, Kroger J, Pischon T, Bergmann MM, Boeing H. Television watching and incident diabetes: Findings from the European Prospective Investigation into Cancer and Nutrition-Potsdam Study. Journal of diabetes. 2010; 2:23-27. [PubMed: 20923471]

13. Warren TY, Barry V, Hooker SP, Sui X, Church TS, Blair SN. Sedentary behaviors increase risk of cardiovascular disease mortality in men. Medicine and science in sports and exercise. 2010; 42:879-885. [PubMed: 19996993]

14. Stamatakis E, Hamer M, Dunstan DW. Screen-based entertainment time, all-cause mortality, and cardiovascular events: population-based study with ongoing mortality and hospital events followup. Journal of the American College of Cardiology. 2011; 57:292-299. [PubMed: 21232666]

15. Pinto Pereira SM, Ki M, Power C. Sedentary behaviour and biomarkers for cardiovascular disease and diabetes in mid-life: the role of television-viewing and sitting at work. PloS one. 2012; 7:e31132. [PubMed: 22347441]

16. Giovannucci E, Ascherio A, Rimm EB, Colditz GA, Stampfer MJ, Willett WC. Physical activity, obesity, and risk for colon cancer and adenoma in men. Annals of internal medicine. 1995; 122:327-334. [PubMed: 7847643]

17. Giovannucci E, Michaud D. The role of obesity and related metabolic disturbances in cancers of the colon, prostate, and pancreas. Gastroenterology. 2007; 132:2208-2225. [PubMed: 17498513]

18. Giovannucci E, Harlan DM, Archer MC, et al. Diabetes and cancer: a consensus report. CA: a cancer journal for clinicians. 2010; 60:207-221. [PubMed: 20554718] 
19. Larsson SC, Orsini N, Wolk A. Diabetes mellitus and risk of colorectal cancer: a meta-analysis. Journal of the National Cancer Institute. 2005; 97:1679-1687. [PubMed: 16288121]

20. Elwing JE, Gao F, Davidson NO, Early DS. Type 2 diabetes mellitus: the impact on colorectal adenoma risk in women. The American journal of gastroenterology. 2006; 101:1866-1871. [PubMed: 16790036]

21. Howard RA, Freedman DM, Park Y, Hollenbeck A, Schatzkin A, Leitzmann MF. Physical activity, sedentary behavior, and the risk of colon and rectal cancer in the NIH-AARP Diet and Health Study. Cancer causes \& control : CCC. 2008; 19:939-953. [PubMed: 18437512]

22. Cong YJ, Gan Y, Sun HL, et al. Association of sedentary behaviour with colon and rectal cancer: a meta-analysis of observational studies. British journal of cancer. 2014; 110:817-826. [PubMed: 24263062]

23. Schmid D, Leitzmann MF. Television viewing and time spent sedentary in relation to cancer risk: a meta-analysis. Journal of the National Cancer Institute. 2014:106. [PubMed: 25174031]

24. Campbell PT, Patel AV, Newton CC, Jacobs EJ, Gapstur SM. Associations of recreational physical activity and leisure time spent sitting with colorectal cancer survival. Journal of clinical oncology : official journal of the American Society of Clinical Oncology. 2013; 31:876-885. [PubMed: 23341510]

25. Arem H, Pfeiffer RM, Engels EA, et al. Pre- and postdiagnosis physical activity, television viewing, and mortality among patients with colorectal cancer in the national institutes of healthAARP diet and health study. Journal of clinical oncology : official journal of the American Society of Clinical Oncology. 2015; 33:180-188. [PubMed: 25488967]

26. Rimm EB, Stampfer MJ, Colditz GA, Giovannucci E, Willett WC. Effectiveness of various mailing strategies among nonrespondents in a prospective cohort study. American journal of epidemiology. 1990; 131:1068-1071. [PubMed: 2343859]

27. Ainsworth BE, Haskell WL, Leon AS, et al. Compendium of physical activities: classification of energy costs of human physical activities. Medicine and science in sports and exercise. 1993; 25:71-80. [PubMed: 8292105]

28. Stampfer MJ, Willett WC, Speizer FE, et al. Test of the National Death Index. American journal of epidemiology. 1984; 119:837-839. [PubMed: 6720679]

29. Meyerhardt JA, Giovannucci EL, Holmes MD, et al. Physical activity and survival after colorectal cancer diagnosis. Journal of Clinical Oncology. 2006; 24:3527-3534. [PubMed: 16822844]

30. McCullough ML, Feskanich D, Stampfer MJ, et al. Diet quality and major chronic disease risk in men and women: moving toward improved dietary guidance. American Journal of Clinical Nutrition. 2002; 76:1261-1271. [PubMed: 12450892]

31. Chiuve SE, Fung TT, Rimm EB, et al. Alternative Dietary Indices Both Strongly Predict Risk of Chronic Disease. J Nutr. 2012; 142:1009-1018. [PubMed: 22513989]

32. Charreire H, Kesse-Guyot E, Bertrais S, et al. Associations between dietary patterns, physical activity (leisure-time and occupational) and television viewing in middle-aged French adults. The British journal of nutrition. 2011; 105:902-910. [PubMed: 21251337]

33. Lynch BM. Sedentary behavior and cancer: a systematic review of the literature and proposed biological mechanisms. Cancer epidemiology, biomarkers \& prevention : a publication of the American Association for Cancer Research, cosponsored by the American Society of Preventive Oncology. 2010; 19:2691-2709.

34. Wijndaele K, Lynch BM, Owen N, Dunstan DW, Sharp S, Aitken JF. Television viewing time and weight gain in colorectal cancer survivors: a prospective population-based study. Cancer causes \& control : CCC. 2009; 20:1355-1362. [PubMed: 19449106]

35. Wannamethee SG, Shaper AG, Lennon L, Whincup PH. Decreased muscle mass and increased central adiposity are independently related to mortality in older men. The American journal of clinical nutrition. 2007; 86:1339-1346. [PubMed: 17991644]

36. Wijndaele K, Healy GN, Dunstan DW, et al. Increased Cardiometabolic Risk Is Associated with Increased TV Viewing Time. Medicine and science in sports and exercise. 2010; 42:1511-1518. [PubMed: 20139784]

37. Koh-Banerjee P, Chu NF, Spiegelman D, et al. Prospective study of the association of changes in dietary intake, physical activity, alcohol consumption, and smoking with 9-y gain in waist 
circumference among 16,587 US men. American Journal of Clinical Nutrition. 2003; 78:719-727. [PubMed: 14522729]

38. Healy GN, Matthews CE, Dunstan DW, Winkler EAH, Owen N. Sedentary time and cardiometabolic biomarkers in US adults: NHANES 2003-06. Eur Heart J. 2011; 32:590-597. [PubMed: 21224291]

39. Cooney RV, Chai W, Franke AA, Wilkens LR, Kolonel LN, Le Marchand L. C-reactive protein, lipid-soluble micronutrients, and survival in colorectal cancer patients. Cancer epidemiology, biomarkers \& prevention : a publication of the American Association for Cancer Research, cosponsored by the American Society of Preventive Oncology. 2013; 22:1278-1288.

40. Schrag D, Cramer LD, Bach PB, Cohen AM, Warren JL, Begg CB. Influence of hospital procedure volume on outcomes following surgery for colon cancer. JAMA : the journal of the American Medical Association. 2000; 284:3028-3035. [PubMed: 11122590]

41. Kim RB, Phillips A, Herrick K, et al. Physical activity and sedentary behavior of cancer survivors and non-cancer individuals: results from a national survey. PloS one. 2013; 8:e57598. [PubMed: 23483916]

42. Bellizzi KM, Rowland JH, Jeffery DD, McNeel T. Health behaviors of cancer survivors: examining opportunities for cancer control intervention. Journal of clinical oncology : official journal of the American Society of Clinical Oncology. 2005; 23:8884-8893. [PubMed: 16314649] 


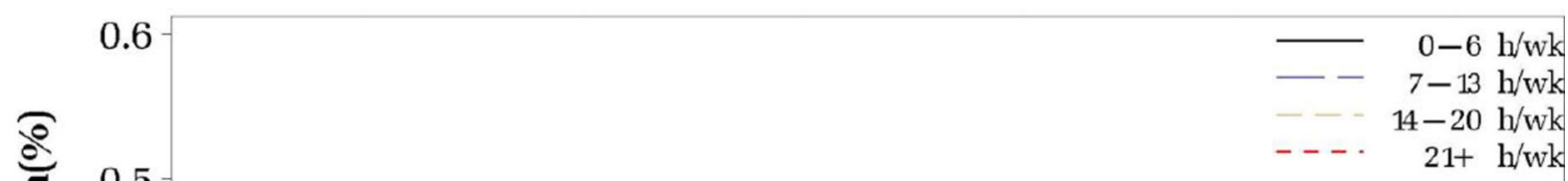

Number at Risk

$0-6 \mathrm{~h} / \mathrm{wk}$

$7-13 \mathrm{~h} / \mathrm{wk}$

$14-20 \mathrm{~h} / \mathrm{wk}$

$21+\mathrm{h} / \mathrm{wk}$

爮 0.1

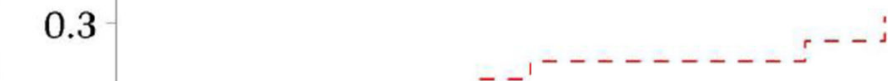

ชู 0.2

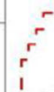

0.0

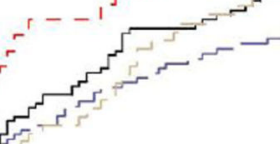

0

0

2

4

6

8

10

12

14

\section{Years since Diagnosis}

$\begin{array}{llllllll}339 & 290 & 263 & 214 & 167 & 133 & 95 & 74 \\ 313 & 278 & 239 & 201 & 161 & 126 & 92 & 62 \\ 180 & 153 & 127 & 103 & 87 & 78 & 63 & 49 \\ 94 & 79 & 65 & 56 & 50 & 35 & 27 & 21\end{array}$




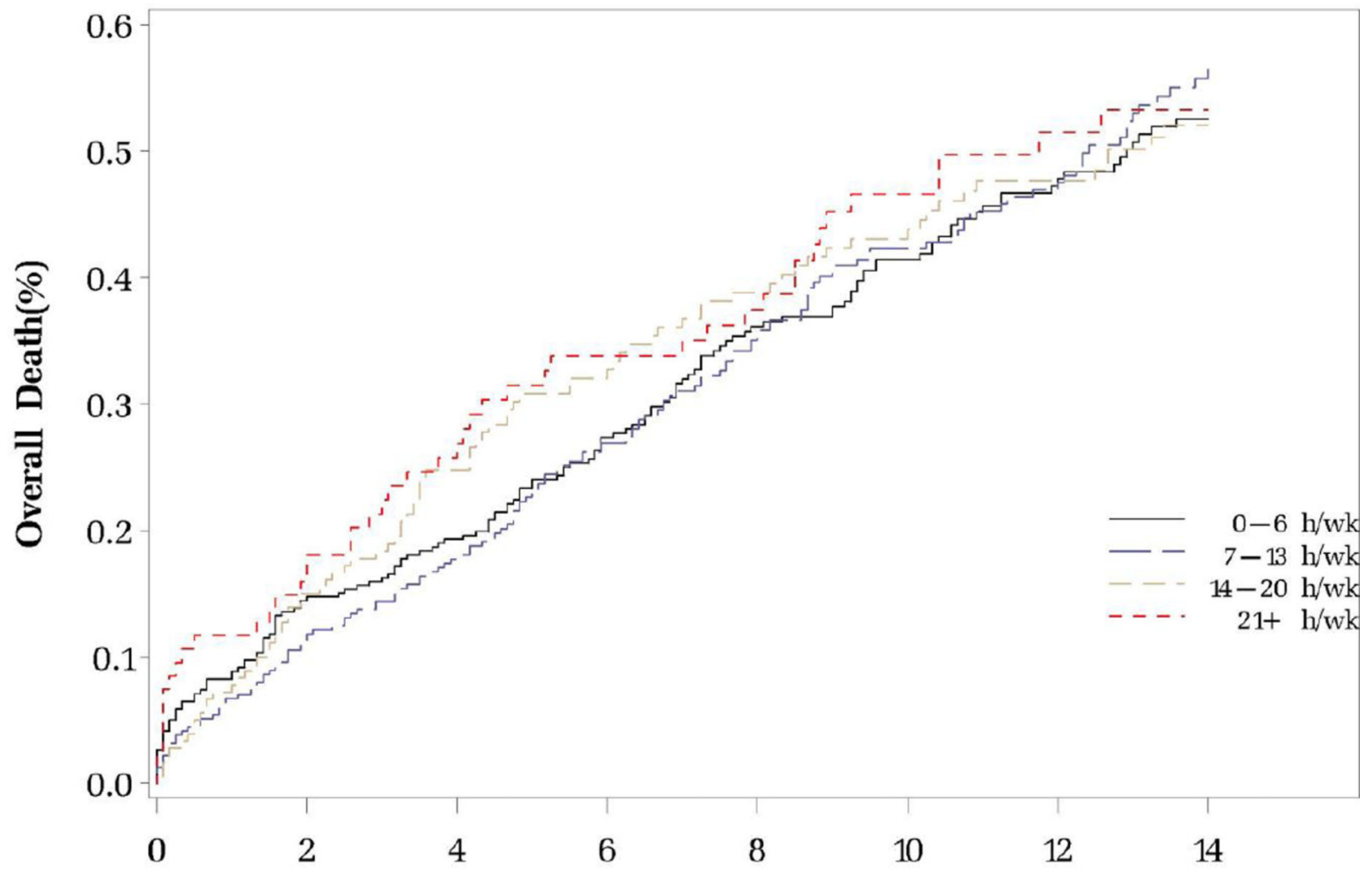

Number at Risk

$0-6 \mathrm{~h} / \mathrm{wk} \quad 339$

$7-13 \mathrm{~h} / \mathrm{wk}$

$14-20 \mathrm{~h} / \mathrm{wk}$

313

180

6

8

10

14

Years since Diagnosis

$21+\mathrm{h} / \mathrm{wk}$

94

290
278
153
79

263

239

127

214

201

103

65

56

167
161
87
50

133
126
78
35

95

92

63

27

74

62

49

Figure 1.

Prediagnostic sitting watching TV and colorectal cancer-specific and overall mortality

A. Colorectal cancer-specific mortality ( $\mathrm{P}$ for log-rank test $=0.02$ )

B. Overall mortality ( $\mathrm{P}$ for log-rank test $=0.83$ ) 
Pinteraction

$\mathrm{HR}(95 \% \mathrm{Cl})$

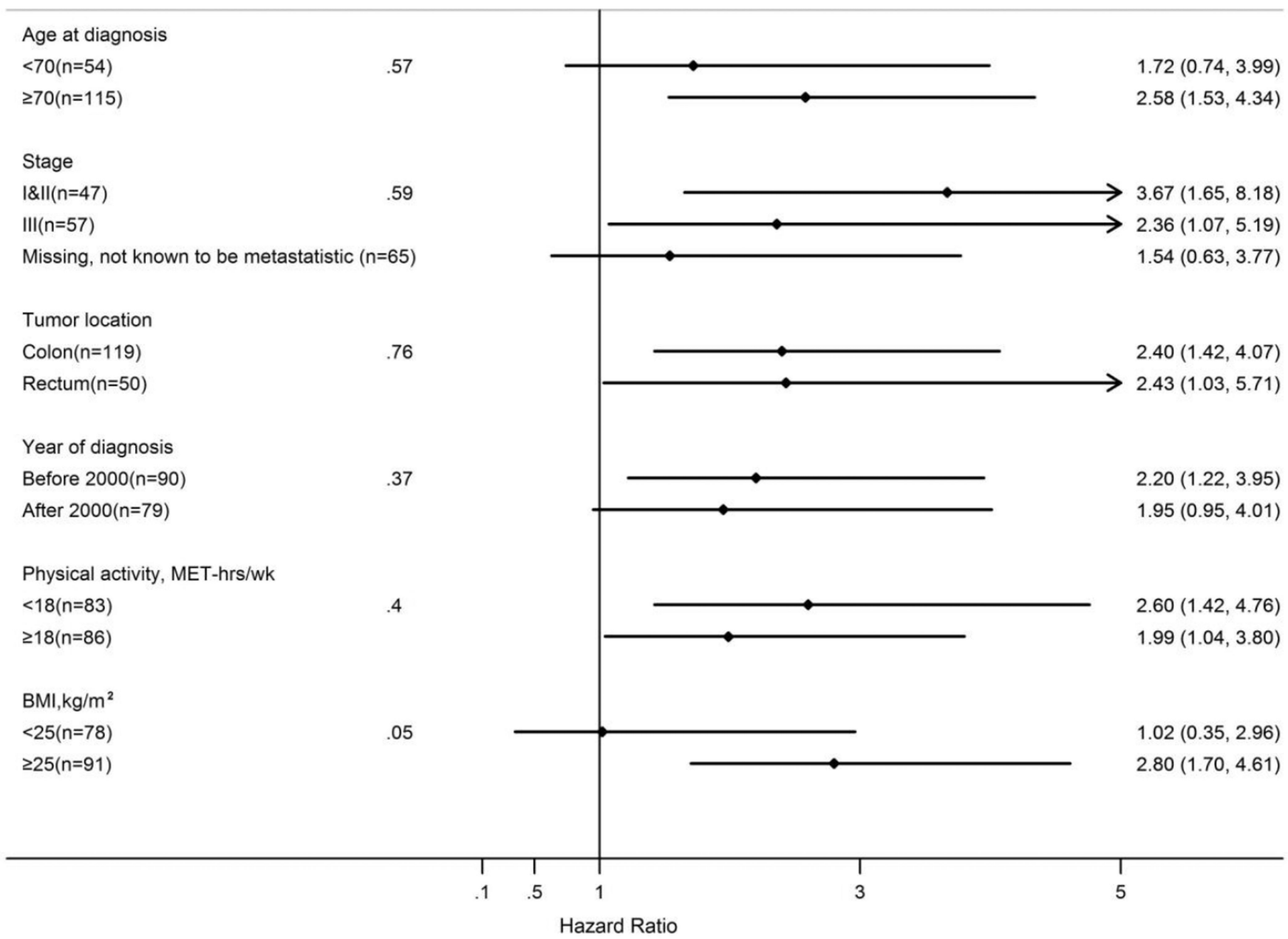

Figure 2.

Stratified analysis of prediagnostic TV watching ( $21 \mathrm{vs}<21 \mathrm{~h} / \mathrm{wk}$ ) and colorectal cancerspecific mortality 


\section{를}
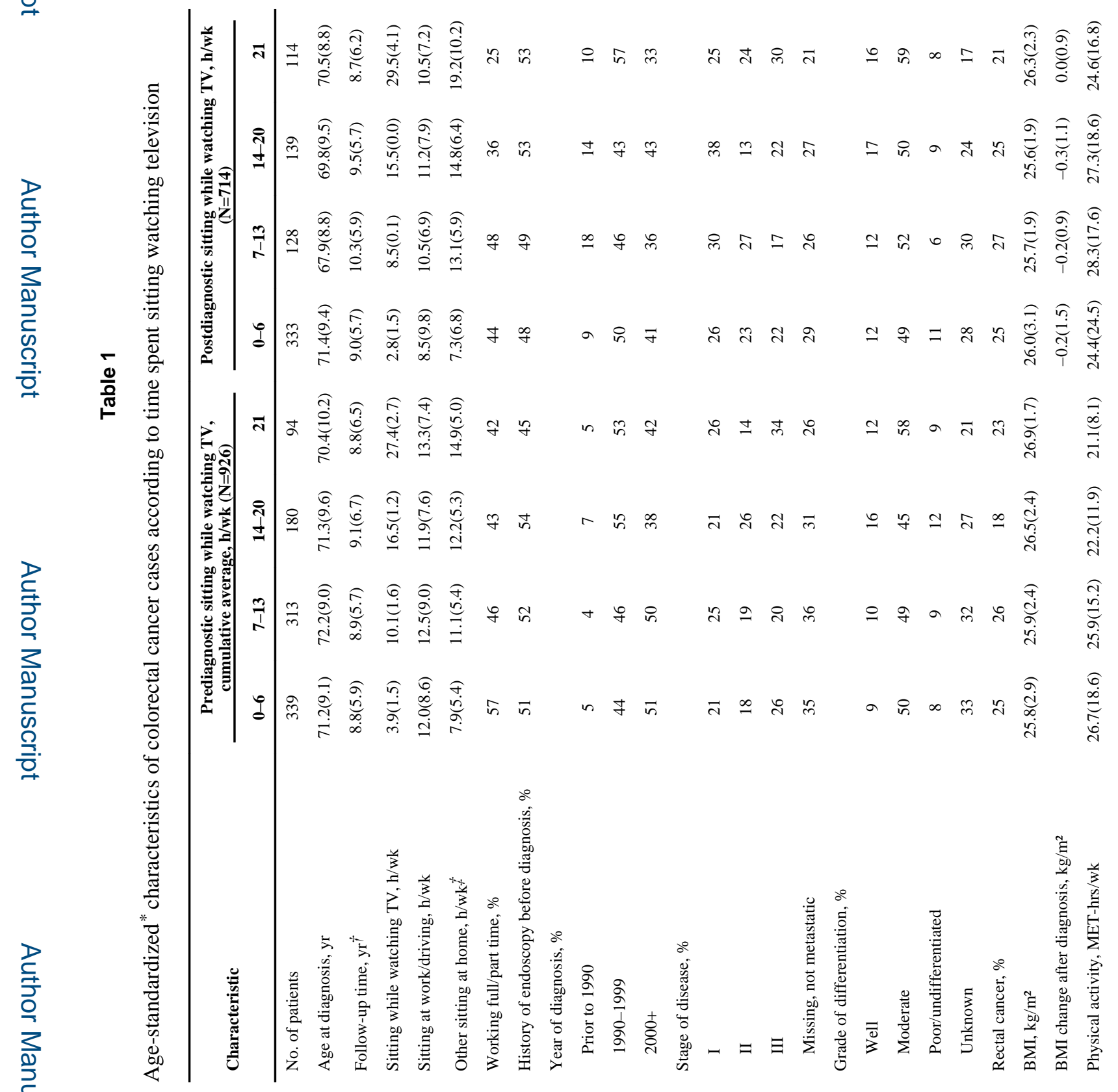

Cancer Causes Control. Author manuscript; available in PMC 2016 October 01. 


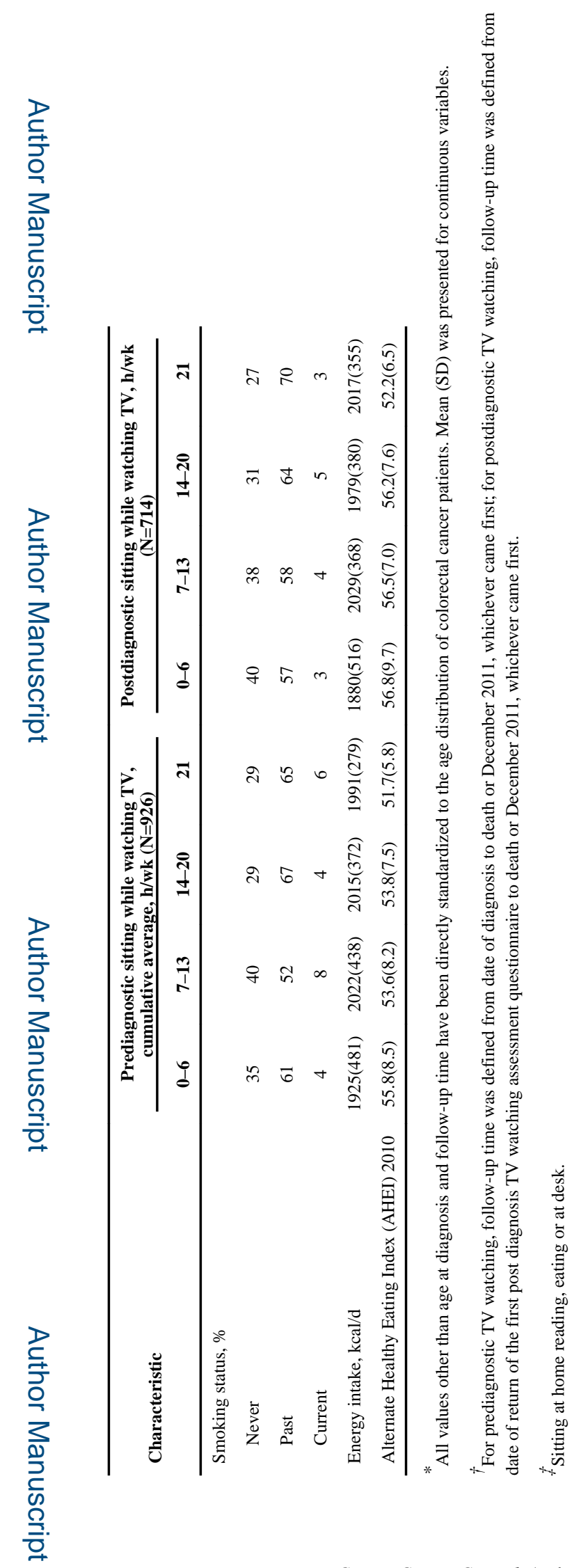




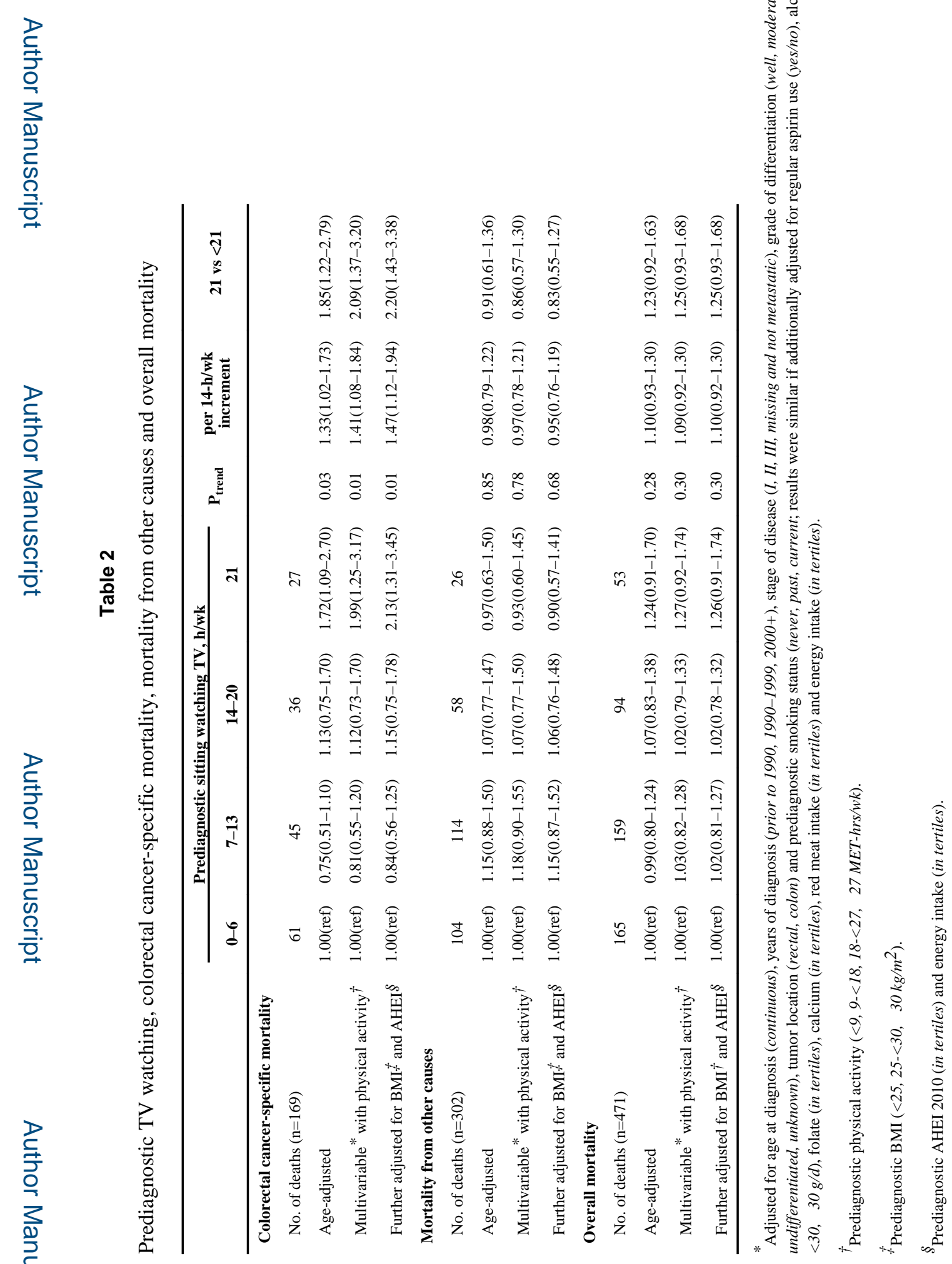

Cancer Causes Control. Author manuscript; available in PMC 2016 October 01. 


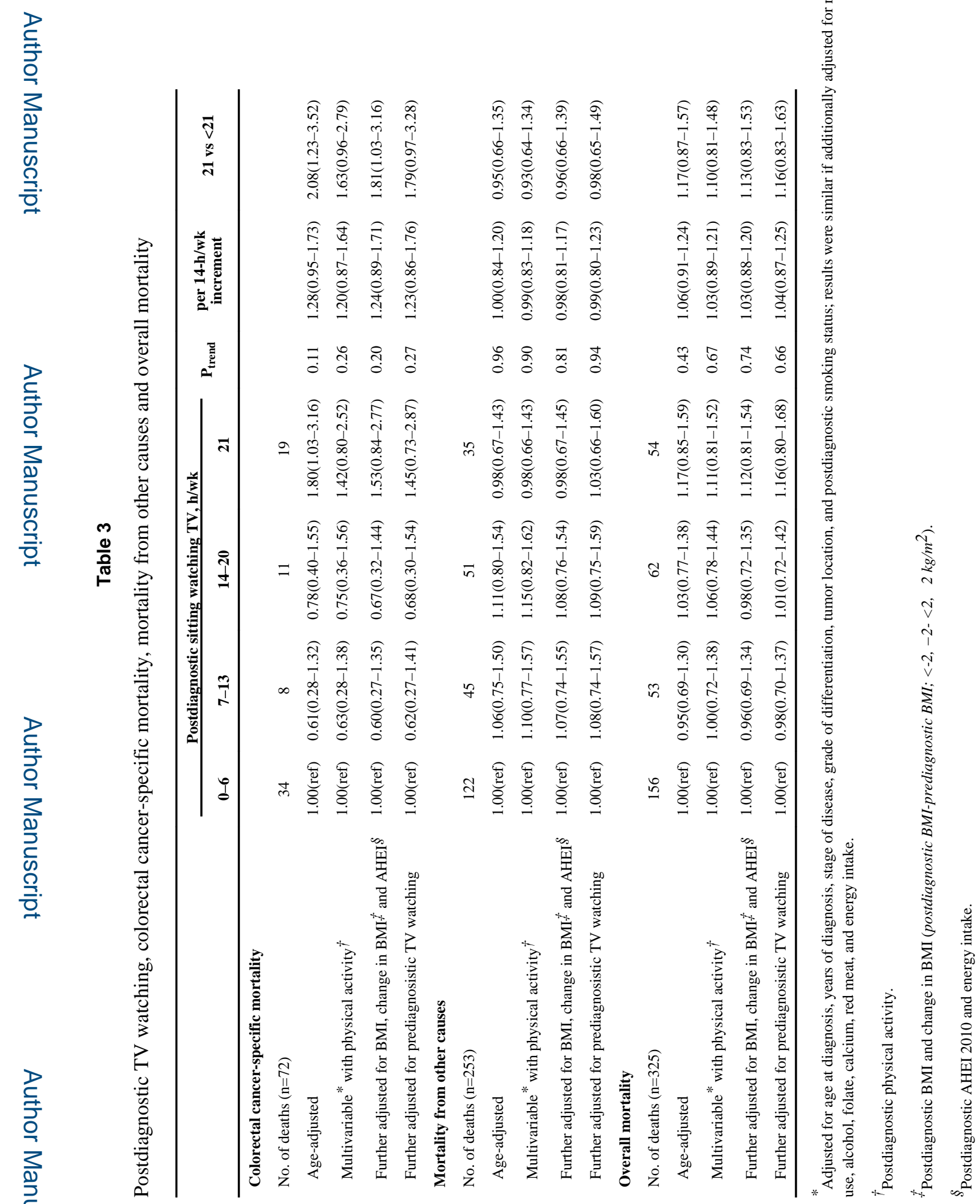

Cancer Causes Control. Author manuscript; available in PMC 2016 October 01. 